\title{
Preparation, Characterization, and Dissociation Properties of Poly(acrylic acid) and Poly(methacrylic acid) with Narrow Molecular Weight Distribution
}

\author{
Seigou KaWaguchi, ${ }^{\dagger}$ Tomoo TaKahashi, ${ }^{* 1}$ Hideki Tajima, ${ }^{* 2}$ Yuji Hirose, ${ }^{* 3}$ and Koichi Ito ${ }^{\dagger}$ \\ Department of Materials Science, Toyohashi University of Technology, \\ Tempaku-cho, Toyohashi 44I, Japan
}

(Received September 18, 1995)

\begin{abstract}
We examined preparation method of poly(acrylic acid) (PAA) and poly(methacrylic acid) (PMeA) with narrow molecular weight distributions (MWDs), over a wide range of molecular weight. The PAA and PMeA were prepared by anionic polymerization of $t$-butyl acrylate (TBA) and $t$-butyl methacrylate (TBMA) in the presence of LiCl [Teyssie $e t$ al., Macromolecules, 20, 1442 (1987)], followed by two-step hydrolysis with $\mathrm{Si}\left(\mathrm{CH}_{3}\right)_{3} \mathrm{I}$ and $\mathrm{HBr}$. The samples obtained were thoroughly characterized by means of size exclusion chromatography, ${ }^{1} \mathrm{H}$ NMR spectroscopy, vapor pressure osmometry, and light scattering for the PTBA and PTBMA, and poly(methyl acrylate) and poly(methyl methacrylate) prepared by the reaction of the PAA and PMeA with diazomethane, respectively. The characterization revealed that PAA and PMeA with narrow MWD can be prepared over the wide range of the molecular weight, $2 \times 10^{3}-8 \times 10^{5}$. Potentiometric titration of the PAA and PMeA with different molecular weights was carried out in the aqueous solution at $25^{\circ} \mathrm{C}$. It was found that the potentiometric titration curve of PMeA strongly depends on the molecular weight, while that of PAA does not. The dependence was observed only in the conformational transition region of the PMeA chain from compact to extended forms.
\end{abstract}

KEY WORDS Poly(acrylic acid) / Poly(methacrylic acid) / Anionic Polymerization / Narrow Molecular Weight Distribution / Dissociation Properties / Conformational Transition / Molecular Weight Dependence / Light Scattering /

Polyelectrolyte is a macromolecule with many ionizable groups along a polymer backbone. The polyelectrolyte shows remarkably characteristic solution behavior different from non-ionic polymers and low molecular weight electrolytes but remains one of the least-understood condensed materials. Although bulk properties such as osmotic pressure and viscosity have been intensively studied for many years, understanding of the solution behavior of polyelectrolytes is lacking. This problem is especially critical because of the fundamental importance of many prototypical polyelectrolytes such as DNA. From an experimental point of view, challenge should be addressed to prepare well-defined polyelectrolytes to carry out several basic measurements.

Poly(acrylic acid) (PAA) and poly(methacrylic acid) (PMeA) are representative synthetic vinylic polyelectrolytes with weak acid functions at every second carbon atom in the main chain. The latter is well-known to show conformational transition from compact to extended form in a low degree of dissociation $(\alpha) .^{1-5}$ While there has been vast literature of the studies on their solution behavior, the samples which have been used so far are not necessarily well-defined from a viewpoint of molecular weight distribution (MWD). It was also pointed out that PAA samples with the MW higher than $10^{6}$, prepared by radical polymerization, contain branching. ${ }^{6}$

One noteworthy study in elucidation of the physical properties of the vinylic polyelectrolyte solution was carried out by Nagasawa and his co-workers in $1977 .{ }^{7}$ They successfully prepared high MW PAA samples with narrow MWDs by anionic polymerization of $t$-butyl acrylate (TBA), followed by hydrolysis. ${ }^{8}$ The studies on the conformational properties such as intrinsic viscosity, small angle X-ray scattering, and the particle scattering factor obtained from light scattering made a great progress in elucidating the nature of the longrange electrostatic interaction within a polyelectrolyte chain. ${ }^{9}$ On the other hand, the theories presented independently by Odijk ${ }^{10}$ and Skolnick and Fixman ${ }^{11}$ emphasized the effect of electrostatic short-range interaction on the global conformation. This has been an unsolved problem in polyelectrolyte field. Nevertheless, little has been carried out on subsequent studies using PAA and PMeA samples with narrow MWDs. One key seems to carry out the experiments in the region of low MW polyelectrolytes, where the long-range interaction can be ignored.

There exits only one synthetic acid-type polyelectrolyte with a narrow MWD, that is, sodium poly(styrenesulfonate) which is commercially available. This fact is one of the reasons why the molecular-level understanding of polyelectrolytes has been less established. We believe that the most important point in the polyelectrolyte field is to establish the preparation method of well-characterized polyelectrolyte samples in large scale over wide range of the molecular weight $\left(10^{2}-10^{7}\right)$, and to use them for several experimental studies, and to compare with the current theories in non-ionic polymer and polyelectrolyte solutions. The time is now when the techniques in the polymer synthesis have been remarkably advanced even for acrylate monomers. Here we

\footnotetext{
${ }^{\dagger}$ To whom correspondence should be addressed.

*1 Present address: Takemoto Oil \& Fat Co., Ltd., 2-5, Minatomachi, Gamagori 443, Japan.

${ }^{* 2}$ Present address: Natoko Paint Co., Ltd., Mizuho-ku, Nagoya 467, Japan.

*3 Present address: Department of Knowledge-based Information Engineering, Toyohashi University of Technology, Tempaku-cho, Toyohashi 44l, Japan.
} 
report the preparation in $10 \mathrm{~g}$ scale, characterization, and dissociation properties of the PAA and PMeA samples over wide range of the MWs.

In anionic polymerization of acrylate monomers, the labile $\alpha$-hydrogen may cause a serious problem in addition to the presence of the carbonyl group. In fact, proton abstraction by both initiator and propagating chain ends often occurs during the polymerization. Recently, Teyssié and his co-workers ${ }^{12,13}$ have observed a striking effect of $\mathrm{LiCl}$, which suppressed such reactions in the polymerization of TBA. The polymers with predictable MWs and relatively narrow MWDs were obtained quantitatively by adding $\mathrm{LiCl}$ to the polymerization system. Reetz ${ }^{14}$ also reported that the metal-free, stable tetrabutylammonium salts of ${ }^{-} \mathrm{SR}$ (where $\mathrm{R}=n$-butyl, phenyl, $\left.\left(\mathrm{CH}_{3}\right)_{3} \mathrm{SiOCH}_{2} \mathrm{CH}_{2}\right)$, ${ }^{-} \mathrm{CR}\left(\mathrm{COOR}^{\prime}\right)_{2}\left(\mathrm{R}, \mathrm{R}^{\prime}=\mathrm{CH}_{3}, \mathrm{CH}_{3} \mathrm{CH}_{2}\right)$, and $-\mathrm{C}\left(\mathrm{CH}_{3}\right)-$ $(\mathrm{CN})_{2}$ were excellent initiators in the polymerization of $n$-butyl acrylate at room temperature. Polymers with relatively narrow MWDs $\left(M_{w} / M_{n}=1.2\right)$ were obtained. Quite recently, Yasuda and his co-worker ${ }^{15}$ have reported that the polymerization of acrylate monomers catalyzed by rare-earth metal complex proceeds in a living manner to afford high MW polymers with extremely narrow MWDs. Thus, the living anionic polymerization of acrylic monomers is greatly improved.

One purpose in the present work is to prepare wellcharacterized PAA and PMeA samples at large scale $(10-20 \mathrm{~g})$ in the MW range of $10^{2}$ to $10^{7}$. We followed, therefore, Teyssié's and Reetz's strategies, and examined the possibility to prepare PAA and PMeA samples which meet our needs. Another purpose is to examine MW dependence of the several physical properties of the polyelectrolytes. Here, we carried out the study of dissociation properties. The electrical properties of polyelectrolyte, such as dissociation equilibrium and counterion condensation have been widely believed to be essentially independent on the MW. It is, however, very interesting to elucidate that in what MW range the characteristic solution properties of polyelectrolyte appear. We observe a clear MW dependence in a transition region of the titration curve of PMeA.

\section{EXPERIMENTAL}

The representative preparation scheme we used for the preparations of PAA and PMeA samples with narrow MWDs is shown below.

\section{Monomers}

TBA and $t$-butyl methacrylate (TBMA) were synthesized by the reaction of acrylic acid (AA) and methacrylic acid (MeA), respectively, with isobutylene in diethyl ether containing a small amount of concentrated $\mathrm{H}_{2} \mathrm{SO}_{4}$ as a catalyst. ${ }^{8}$ The TBA and TBMA synthesized were distilled two times over $\mathrm{CaH}_{2}$ under reduced pressure and one time over sodium mirror under high vacuum, and divided into several ampoules with a break-seal in appropriate amounts $(c a .10-20 \mathrm{~g})$. The monomers were further purified with hexane solution of triethyl aluminium just before polymerization, ${ }^{16}$ and diluted with tetrahydrofuran (THF).

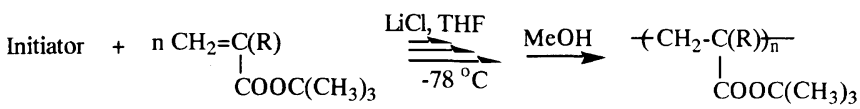

$$
\begin{aligned}
& \underset{\text { dry-Acetone }}{\stackrel{\mathrm{Si}\left(\mathrm{CH}_{3}\right)_{3} \mathrm{I}}{\longrightarrow}} \underset{\text { Water }}{\stackrel{\mathrm{HBr}}{\longrightarrow}}+\underset{\text { COOH }}{\left.+\mathrm{CH}_{2}-\mathrm{C}(\mathrm{R})\right)_{\mathrm{n}}} \underset{\text { Benzene }}{\stackrel{\mathrm{CH}_{2} \mathrm{~N}_{2}}{\longrightarrow}}+\underset{\mathrm{COOCH}_{3}}{\left.+\mathrm{CH}_{2}-\mathrm{C}(\mathrm{R})\right)_{n}} \\
& \text { R: } \mathrm{H} \text { (TBA) or/and } \mathrm{CH}_{3} \text { (TBMA) }
\end{aligned}
$$

$\begin{array}{cc} & \mathrm{CH}_{3} \\ \text { Initiators: } & \mathrm{CH}_{3}-\bigodot^{-} \mathrm{Li}^{+} \\ & \mathrm{COOC}\left(\mathrm{CH}_{3}\right)_{3} \\ & (\mathrm{BLIB})\end{array}$

$$
\begin{gathered}
\mathrm{CH}_{3} \\
\mathrm{CH}_{3}-\mathrm{C}^{-} \mathrm{N}^{+}(\mathrm{Bu})_{4} \\
\int_{\mathrm{COOC}\left(\mathrm{CH}_{3}\right)_{3}} \\
(\mathrm{BAIB})
\end{gathered}
$$

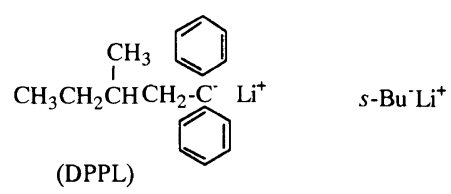

\section{Solvents}

THF was refluxed over sodium wire, distilled from $\mathrm{LiAlH}_{4}$, and sodium anthracenide solution, and finally distilled from oligo( $\alpha$-methylstyryl)dipotassium solution, which was prepared by the reaction of potassium with $\alpha$-methylstyrene in THF and divided into several ampoules. Hexane was distilled with hexane solution of $n$-butyllithium and divided into several glass ampoules. Ten grams of $\mathrm{LiCl}(99.99+\%)$ were dried under high vacuum at $130^{\circ} \mathrm{C}$ over $24 \mathrm{~h}$ and dissolved in $200 \mathrm{~mL}$ of THF.

\section{Initiators}

Several types of initiator were examined in anionic polymerizations of TBA and TBMA. They include $s$-butyllithium, 1,1-diphenyl-3-methylpentyllithium (DPPL), $t$-butyl $\alpha$-lithioisobutyrate (BLIB), diethyl $\alpha$ tetrabutylammonium ethylmalonate (BAEM), and $t$ butyl $\alpha$-tetrabutylammonium isobutyrate (BAIB). DPPL was prepared by the reaction of $s$-butyllithium with 1,1-diphenylethylene in THF. BLIB was synthesized in an all glass reactor under high vacuum by the reaction of $t$-butyl isobutyrate with lithium diisopropylamide which was prepared by the reaction of $n$-butyllithium with diisopropylamine. ${ }^{17,18}$ Several steps were carried out in one apparatus. The structure of BLIB was confirmed by in-situ ${ }^{1} \mathrm{H}$ NMR measurement in dimethylsulfoxide- $d_{6}$. The yield was $94.4 \%$, based on $n$-butyllithium used. BAEM and BAIB were similarly synthesized by the reaction of diethyl ethylmalonate and $t$-butyl isobutylate with $\mathrm{NaH}$ in THF, followed by the addition of tetrabutylammonium bromide. The structure was confirmed with ${ }^{1} \mathrm{H}$ NMR. All the initiator concentrations were determined by potentiometric titration with known concentration of potassium hydrogen phthalate.

\section{Polymerization}

All anionic polymerizations were carried out at $-78^{\circ} \mathrm{C}$ under high-vacuum $\left(\sim 10^{-5} \mathrm{mmHg}\right)$ in an all-glass apparatus equipped with break-seals in the usual manner. Before polymerization, the glass apparatus was cleaned with an oligo( $\alpha$-methylstyryl)dipotassium THF 
solution to kill any impurities. The desired charge of the monomers in THF solution was added to a THF solution containing initiator and $\mathrm{LiCl}$ with vigorous stirring. Both solutions must be kept at $-78^{\circ} \mathrm{C}$. The polymerization was then terminated with methanol at $-78^{\circ} \mathrm{C}$, after appropriate polymerization time. The polymer was precipitated by pouring the mixture into a large amount of methanol containing water (10-50 $\mathrm{wt} \%$ ). The precipitates were collected onto a glass filter and freeze-dried from benzene.

\section{Hydrolysis}

PAA and PMeA were prepared by two-step hydrolysis of PTBA and PTBMA, respectively. First, they were dissolved in dry acetone containing 1.5 molar fold amount of NaI. The same amount of $\mathrm{Si}\left(\mathrm{CH}_{3}\right)_{3} \mathrm{Cl}$ was added dropwise to the solution and refluxed under $\mathrm{Ar}$ atmosphere. ${ }^{19,20}$ Upon the reaction, PAA and PMeA began to precipitate. The precipitates were collected onto glass filter, washed quickly with dry acetone, and dried in vacuum. Second, the PAA and PMeA samples were further hydrolyzed with $48 \% \mathrm{HBr}$. PAA and PMeA were dissolved in water and refluxed with $\mathrm{HBr}$ solution for 48 hours. After $\mathrm{pH}$ of the solution was adjusted to 7 with $\mathrm{NaOH}$ solution, the solution was dialyzed against de-ionized water, passed through a mixed bed of ionic exchange resins, and finally freeze-dried. This two-step hydrolysis is necessary to convert completely PTBA and PTBMA, especially for high MW samples, as will be discussed later. To characterize PAA and PMeA thus prepared, a part of PAA and PMeA were converted to poly(methyl acrylate) (PMA) and poly(methyl methacrylate) (PMMA), respectively, by reacting them with diazomethane in benzene-ether solution for 48 hours at room temperature.

\section{Measurements \\ ${ }^{1} \mathrm{H}$ NMR spectra were recorded on a JEOL $270 \mathrm{MHz}$} FT-NMR spectrometer in $\mathrm{CDCl}_{3}$ and $\mathrm{D}_{2} \mathrm{O}$. Size exclusion chromatography (SEC) for the characterization of MWDs was run at $40^{\circ} \mathrm{C}$ with a JASCO TRIROTAR-III instrument with a refractive index detector. The elution volume was calibrated with a series of polystyrene (Tosoh Co., Japan) and PMMA (Showa Denko K.K., Japan) standards. THF was used as an eluent at a flow rate of $1.0 \mathrm{~mL} \mathrm{~min}^{-1}$. Vapor pressure osmometry (VPO) measurements for $M_{n}$ determination were made with a Corona 117 instrument in benzene solutions at $50 \pm$ $0.05^{\circ} \mathrm{C}$. 1,2-Diphenylethane which was dried in vacuum for 48 hours was used as a standard material for the calibration. Light scattering measurements for $M_{w}$ determination were made at $25 \pm 0.1^{\circ} \mathrm{C}$ with a modified LS-601, Union Gikken Co., Japan, equipped with a vertically polarized light of $10 \mathrm{~mW} \mathrm{He}-\mathrm{Ne}$ laser of $632.8 \mathrm{~nm}$ as an incident beam. The scattered intensity of spectral grade benzene at $90^{\circ}$ was used for optical calibration. The intensities of scattered light were measured at scattering angles $\theta=20-130^{\circ}$. For optical clarification, all the sample solutions were filtered slowly and directly into light scattering cells with $0.2-\mu \mathrm{m}$ PTFE filters (Advantec Toyo Co., Japan). The refractive index increment $(\mathrm{d} n / \mathrm{d} c)$ was measured at $25^{\circ} \mathrm{C}$ with a refractometer, RM-102, Otsuka Electronics, Co., Ltd.
The equipment was calibrated using a series of $\mathrm{KCl}$ aqueous solutions.

Potentiometric titration was carried out at $25^{\circ} \mathrm{C}$ with an Orion Research EA-920 ion analyzer with a Ross-pH complex glass electrode Model 8102 under Ar atmosphere. The solutions of PAA and PMeA for the measurements were prepared by passing them again through a mixed bed of ionic exchange resins and adding a required amount of $\mathrm{NaCl}$ to them just before measurement. The detailed procedures were described in the previous paper. ${ }^{21}$

\section{RESULTS AND DISCUSSION}

\section{Anionic Polymerization of TBA}

The results of anionic polymerization of TBA are summarized in Table I. We first seek the possibility of preparing narrow MWD PTBAs using metal-free initiators reported by Reetz et al. ${ }^{14}$ They prepared poly( $n$-butyl acrylate)s with $M_{w} / M_{n}=1.16-1.36$ at room temperature. One finds that the initiator, BAEM, effectively polymerizes TBA at $-78^{\circ} \mathrm{C}$ to afford PTBA with relatively narrow MWD ( 1.3) (run 2-4), whereas all the polymerizations using alkyllithium as an initiator result in very broad MWD (2-3.5) polymers, irrespective of the types of the alkyl group in the initiator. DPPL, which is a favorable initiator for the polymerization of methacrylate monomers, is ineffective for the TBA polymerization. The effectiveness of the metal-free initiator seems to be consistent with Reetz's results but MWD of the polymer obtained is not so narrow as we expected and not reproducible. Also, one could not prepare narrow MWD PTBA at $0^{\circ} \mathrm{C}$ and room temperature (run 6,7 ). When BAIB which consists of $t$-butyl isobutylate and tetrabutylammonium is used, the polymerization could not be controlled $\left(M_{w} / M_{n}=3.1_{9}\right)$ (run 8).

Second, we examine the effectiveness of $\mathrm{LiCl}$ addition. One finds in this table that the greater the $[\mathrm{LiCl}] /[\mathrm{BLIB}]$ the narrower is the MWD of the polymers. In consistent with Teyssié's results, ${ }^{12}$ when the ratio, $[\mathrm{LiCl}] /[$ Initiator] is greater than 5, the MWD becomes remarkably narrow. The initiator efficiencies of BLIB prepared are similar to each other in all the polymerizations and are ca. $40 \sim 50 \%$ at $-78^{\circ} \mathrm{C}$. It can be concluded from these polymerization results that $\mathrm{PTBA}$ samples with relatively narrow MWDs can be prepared in MW range of 400 to $2.1 \times 10^{5}$ in the presence of $\mathrm{LiCl}$. Although we tried several times to prepare PTBA samples with MW higher than $2.1 \times 10^{5}$, the polymerization did not take place, or did proceed but afford the polymers with MWD broader than 1.5. Klein et al. ${ }^{25}$ tried to prepare such high MW PTBA using Teyssié's method under argon atmosphere. But they also could not prepare a narrow MWD PBMA with MW higher than $6 \times 10^{4}$. Further technical efforts are necessary about this point.

\section{Anionic Polymerization of TBMA}

In Table II, the polymerization results of TBMA are presented. The initiator, DPPL with a large steric hindrance around the reactive center is found to be an excellent initiator for the preparation of PTBMA with fairly narrow MWDs. If $\mathrm{LiCl}$ is added to the reaction, 
Table 1. Anionic polymerization results of TBA

\begin{tabular}{|c|c|c|c|c|c|c|c|c|c|c|c|}
\hline \multirow{2}{*}{ Run } & \multirow{2}{*}{ Initiator } & \multirow{2}{*}[\mathrm{I}]{$/ \mathrm{mmol}$} & \multirow{2}{*}[\mathrm{TBA}]{$/ \mathrm{mmol}$} & \multirow{2}{*}{$\mathrm{THF} / \mathrm{mL}$} & \multirow{2}{*}[\mathrm{TBA}]{$/[\mathrm{I}]$} & \multirow{2}{*}[\mathrm{LiCl}]{$/[\mathrm{I}]$} & \multirow{2}{*}{$\operatorname{Temp} /{ }^{\circ} \mathrm{C}$} & \multicolumn{2}{|c|}{ РTBA } & \multicolumn{2}{|c|}{ PMA } \\
\hline & & & & & & & & $10^{-3} M_{n}^{\mathrm{a}}$ & $M_{w} / M_{n}^{\mathrm{a}}$ & $10^{-3} M_{n}^{\mathrm{a}}$ & $M_{w} / M_{n}{ }^{\mathrm{a}}$ \\
\hline 1 & DPPL & 0.67 & 78 & 150 & 116 & 0 & -78 & 101 & $2.1_{9}$ & & \\
\hline 2 & BAEM & 0.46 & 76 & 150 & 165 & 0 & -78 & 227 & 1.29 & & \\
\hline 3 & BAEM & 0.51 & 81 & 160 & 159 & 0 & -78 & 125 & $1.4_{2}$ & & \\
\hline 4 & BAEM & 0.91 & 78 & 145 & 86 & 0 & -78 & 85 & $1.2_{3}$ & & \\
\hline 6 & BAEM & 0.84 & 60 & 110 & 71 & 0 & 0 & 15 & $2.8_{4}$ & & \\
\hline 7 & BAEM & 0.84 & 100 & 105 & 119 & 0 & 25 & 6.8 & $3.3_{9}$ & & \\
\hline 8 & BAIB & 0.67 & 79 & 145 & 118 & 0 & -78 & 120 & $3.1_{9}$ & & \\
\hline 9 & BLIB & 0.68 & 80 & 200 & 118 & 0 & -78 & 110 & $3.3_{4}$ & & \\
\hline 10 & BLIB & 0.71 & 85 & 150 & 120 & 1.35 & -78 & 130 & $1.5_{3}$ & & \\
\hline 11 & BLIB & 15.5 & 31 & 120 & 2 & 8.70 & -78 & 0.40 & $1.2_{6}$ & & \\
\hline 12 & BLIB & 7.3 & 80 & 110 & 11 & 6.78 & -78 & $3.2^{\mathrm{b}}$ & $1.1_{8}$ & & \\
\hline 13 & BLIB & 5.0 & 85 & 106 & 17 & 7.26 & -78 & 4.4 & $1.2_{1}^{\circ}$ & 2.9 & $1.2_{0}$ \\
\hline 15 & BLIB & 1.87 & 140 & 250 & 75 & 5.95 & -78 & 24 & $1.1_{1}$ & 17 & $1.1_{1}$ \\
\hline 16 & BLIB & 0.99 & 160 & 340 & 161 & 7.11 & -78 & $46^{\mathrm{c}}$ & $1.1_{8}$ & 32 & $1.1_{8}$ \\
\hline 17 & BLIB & 0.19 & 156 & 560 & 821 & 8.17 & -78 & $212^{\mathrm{d}}$ & $1.1_{6}$ & 125 & $1.1_{4}^{\circ}$ \\
\hline
\end{tabular}

${ }^{\mathrm{a}}$ Determined by SEC calibrated with a series of polystyrene standards. $\quad{ }^{\mathrm{b}} M_{n}(\mathrm{VPO})=3.8 \times 10^{3} . \quad{ }^{\mathrm{c}} M_{w}(\mathrm{LS})=5.8 \times 10^{4} . \quad{ }^{\mathrm{d}} M_{w}(\mathrm{LS})=2.71 \times 10^{5}$ DPPL, 1,1-diphenyl-3-methylpentyllithium; BAEM, diethyl $\alpha$-tetrabutylammonium ethylmalonate; BAIB, $t$-butyl $\alpha$-tetrabutylammonium isobutyrate; BLIB, $t$-butyl $\alpha$-lithioisobutyrate.

Table II. Anionic polymerization results of $\mathrm{TBMA}^{\mathrm{a}}$

\begin{tabular}{|c|c|c|c|c|c|c|c|c|c|c|}
\hline \multirow{2}{*}{ Run } & \multirow{2}{*}{ Initiator } & \multirow{2}{*}[\mathrm{I}]{$/ \mathrm{mmol}$} & \multirow{2}{*}[\mathrm{TBMA}]{$/ \mathrm{mmol}$} & \multirow{2}{*}{$\mathrm{THF} / \mathrm{mL}$} & \multirow{2}{*}[\mathrm{TBA}]{$/[\mathrm{I}]$} & \multirow{2}{*}[\mathrm{LiCl}]{$/[\mathrm{I}]$} & \multicolumn{2}{|c|}{ PTBMA } & \multicolumn{2}{|c|}{ PMMA } \\
\hline & & & & & & & $10^{-3} M_{n}^{\mathrm{b}}$ & $M_{w} / M_{n}^{\mathrm{b}}$ & $10^{-3} M_{n}^{\mathrm{b}}$ & $M_{w} / M_{n}^{\mathrm{b}}$ \\
\hline 1 & $s$-BuLi & 0.64 & 70 & 150 & 109 & 0 & 1960 & $1.4_{5}$ & & \\
\hline $1-D^{c}$ & & & & & & & 1680 & $1.1_{5}$ & & \\
\hline 2 & DPPL & 1.07 & 75 & 136 & 70 & 0 & 10 & $1.3_{7}$ & & \\
\hline 3 & DPPL & 1.10 & 80 & 140 & 73 & 0 & 13 & $1.3_{3}$ & & \\
\hline 4 & DPPL & 0.76 & 80 & 140 & 105 & 0 & 15 & $1.0_{8}$ & & \\
\hline 5 & DPPL & 0.43 & 73 & 145 & 170 & 0 & 30 & $1.1_{4}$ & & \\
\hline 6 & DPPL & 0.071 & 75 & 210 & 1056 & 0 & 190 & $1.0_{9}$ & 176 & $1.0_{8}$ \\
\hline 7 & DPPL & 0.057 & 200 & 850 & 3509 & 0 & 1160 & $1.6_{5}$ & & \\
\hline 8 & DPPL & 2.61 & 60 & 120 & 23 & 5.04 & 2.3 & $1.0_{7}$ & 1.5 & $1.0_{7}$ \\
\hline 9 & BLIB & 3.04 & 70 & 110 & 23 & 7.81 & 11 & $1.0_{9}$ & 10 & $1.0_{9}$ \\
\hline 10 & DPPL & 2.31 & 162 & 135 & 70 & 5.25 & 13 & $1.0_{4}$ & 10.5 & $1.0_{5}$ \\
\hline 11 & DPPL & 0.76 & 160 & 155 & 210 & 6.78 & 39 & $1.0_{3}$ & 29 & $1.0_{4}$ \\
\hline 12 & DPPL & 0.28 & 140 & 125 & 500 & 5.15 & 61 & $1.0_{4}$ & & \\
\hline 13 & DPPL & 0.54 & 170 & 155 & 315 & 5.08 & 78 & $1.0_{4}$ & 58 & $1.0_{5}$ \\
\hline 14 & DPPL & 0.20 & 145 & 150 & 725 & 7.81 & 80 & $1.0_{4}$ & & \\
\hline 15 & DPPL & 0.18 & 120 & 350 & 667 & 8.01 & 136 & $1.1_{0}^{4}$ & 96 & $1.1_{1}$ \\
\hline 16 & DPPL & 0.059 & 140 & 300 & 2373 & 8.17 & 310 & $1.0_{6}$ & 187 & $1.0_{7}$ \\
\hline 17 & DPPL & 0.083 & 180 & 680 & 2169 & 7.53 & 342 & $1.1_{1}$ & & \\
\hline 18 & DPPL & 0.026 & 200 & 870 & 7692 & 3.65 & 910 & $1.3_{0}$ & 693 & $1.2_{9}$ \\
\hline
\end{tabular}

${ }^{a}$ All polymerizations were carried out at $-78^{\circ} \mathrm{C}$. ${ }^{\mathrm{b}}$ Determined by SEC calibrated with a series of polystyrene standards. ${ }^{\mathrm{c}}$ The sample (run 1) was subjected to solvent-nonsolvent fractionation using toluene as solvent and methanol/water mixtures as nonsolvent. $M_{w}=1.5_{1} \times 10^{6}$ was determined from the light scattering measurement as shown in Figure 3. $s$-BuLi, s-butyllithium; DPPL, 1,1-diphenyl-3-methylpentyllithium; BLIB, $t$-butyl- $\alpha$-lithioisobutyrate.

the polymerization always gives PTBMA polymers with extremely narrow MWDs. One concludes that the PTBMA with narrow MWD can be prepared over MW range of $2.3 \times 10^{3}$ to $3.0 \times 10^{5}$ by the polymerization using DPPL as an initiator in the presence of $\mathrm{LiCl}$. The polymerization, however, is unsatisfactory to prepare PTBMA with MW higher than ca. $3.0 \times 10^{5}$, as the case of PTBA. Much effort in the purification of all the chemicals used and in the polymerization techniques is necessary and now in progress.

\section{Hydrolysis}

There are several methods for the hydrolysis of $t$-butyl ester polymers. They include acid- $\left(\mathrm{HBr},{ }^{8} p\right.$-toluenesul- fonic acid $^{23}$ ) and base-catalyzed hydrolysis, pyrolysis, and $\left(\mathrm{CH}_{3}\right)_{3} \mathrm{SiI}{ }^{19,20,24}$ We chose $\left(\mathrm{CH}_{3}\right)_{3} \mathrm{SiI}$ method because one can carry out the reaction under a mild condition, when compared to the first three methods. However, we encountered a difficulty in the hydrolysis of PTBA and PTBMA with the MW higher than $c a$. $5 \times 10^{4}$.

In Figure 1(a) and (b), are shown ${ }^{1} \mathrm{H}$ NMR spectra of PTBA and PAA hydrolyzed by $\mathrm{Si}\left(\mathrm{CH}_{3}\right)_{3} \mathrm{I}$ in acetone at $60^{\circ} \mathrm{C}$ for 4 hours. One observes a small peak due to $t$-butyl peak in the spectrum of the PAA. The degree of hydrolysis is $96 \%$. It was found that for lower MW PTBA than $5 \times 10^{4}$ the degree of hydrolysis was $100 \%$, but decreased with increasing MW. This can be due to 


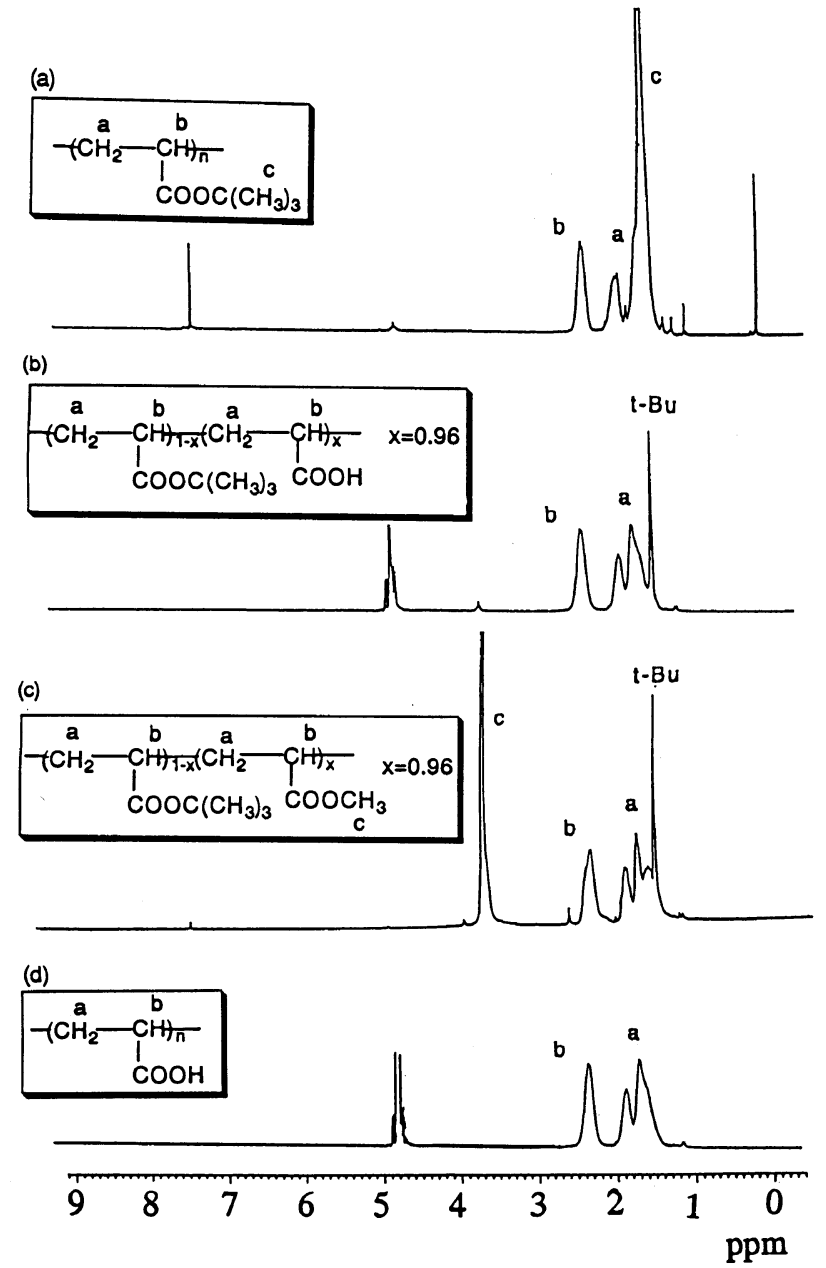

Figure 1. 270-MHz ${ }^{1} \mathrm{H}$ NMR spectra of (a) PTBA (run 16 in Table I), (b) PAA prepared by hydrolysis of the PTBA with $\mathrm{Si}\left(\mathrm{CH}_{3}\right)_{3} \mathrm{I}$, (c) PMA prepared by the reaction of the PAA with $\mathrm{CH}_{2} \mathrm{~N}_{2}$, and (d) PAA prepared by hydrolysis of PTBA with $\mathrm{Si}\left(\mathrm{CH}_{3}\right)_{3} \mathrm{I}$, followed by $\mathrm{HBr}$.

heterogeneity of the reaction under acidic condition. The hydrolyzed PTBA, that is, a copolymer of acrylic acid (AA) and TBA precipitates from acetone solution before complete hydrolysis. If the composition of the copolymer of AA and TBA is constant, the greater the $\mathrm{MW}$, the faster the precipitation in a non-solvent takes place. That is, the degree of hydrolysis decreases with increasing MW. The PAA samples were, therefore, again subjected to hydrolysis in the presence of $\mathrm{HBr}^{8}$ ${ }^{1} \mathrm{H}$ NMR spectrum of the PAA after the second hydrolysis with $\mathrm{HBr}$ is shown in Figure 1(d). One sees that the peak ascribed to $t$-butyl group completely disappeared, implying the complete transformation from PTBA to PAA.

The situation for hydrolysis of PTBMA is further difficult. In Figure 2(a) and (b), are presented ${ }^{1} \mathrm{H}$ NMR spectra of PTBMA and PMeA hydrolyzed by $\mathrm{Si}\left(\mathrm{CH}_{3}\right)_{3} \mathrm{I}$ in acetone at $60^{\circ} \mathrm{C}$ for 8 hours. In ${ }^{1} \mathrm{H}$ NMR spectrum of the PMeA, one can not clearly observe the peak due to residual $t$-butyl group. However, as shown in Figure 2(c), ${ }^{1} \mathrm{H}$ NMR spectrum of the methylated polymer, poly(methyl methacrylate) (PMMA) prepared by the reaction of the PMeA with diazomethane clearly shows the existence of the residual $t$-butyl groups. The degree of hydrolysis was determined to be $85 \%$ from this spectrum. This result strongly implies to us that it is

Polym. J., Vol. 28, No. 9, 1996
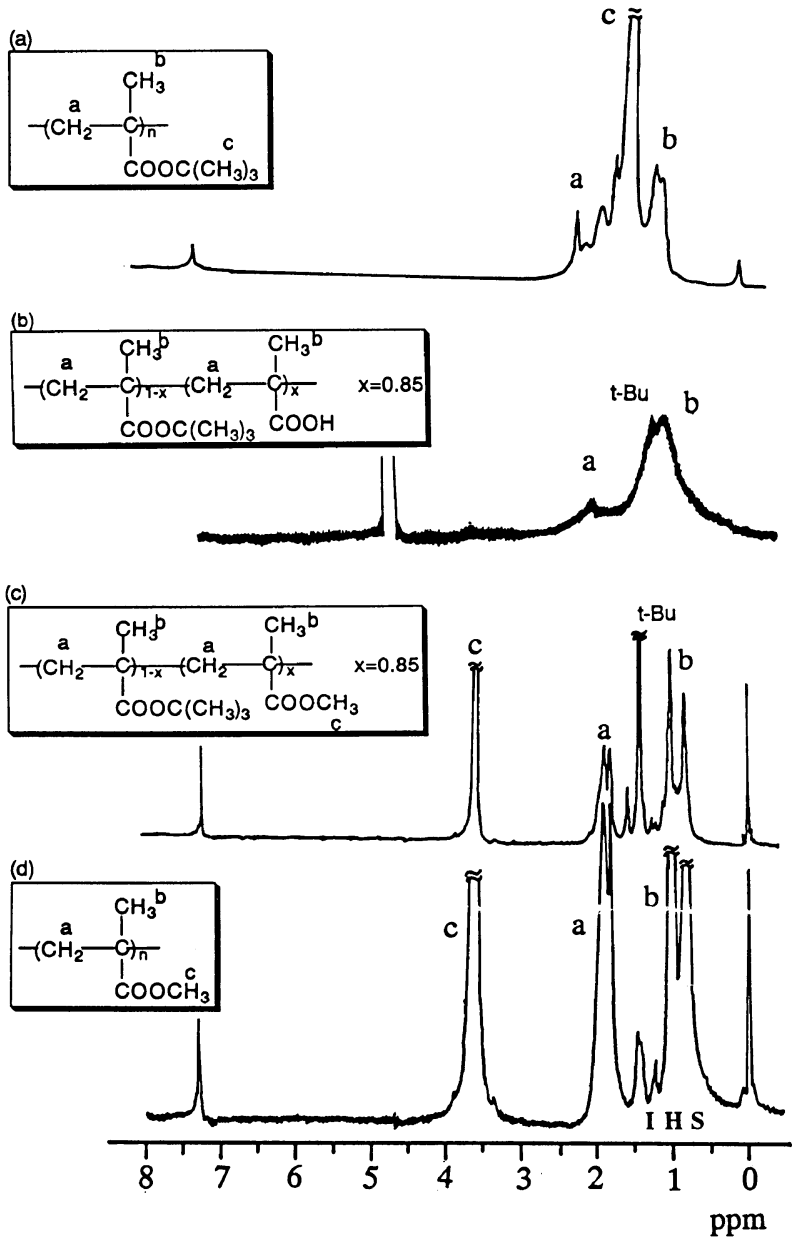

Figure 2. ${ }^{1} \mathrm{H}$ NMR spectra of (a) PTBMA (run 16 in Table II), (b) PMeA prepared by hydrolysis of the PTBMA with $\mathrm{Si}\left(\mathrm{CH}_{3}\right)_{3} \mathrm{I}$, (c) PMMA prepared by the reaction of the PMeA with $\mathrm{CH}_{2} \mathrm{~N}_{2}$, and (d) PMMA prepared by the reaction of $\mathrm{CH}_{2} \mathrm{~N}_{2}$ with PMeA hydrolyzed with $\mathrm{Si}\left(\mathrm{CH}_{3}\right)_{3} \mathrm{I}$, followed by $\mathrm{HBr} .{ }^{1} \mathrm{H}$ NMR measurement conditions are $C_{\mathrm{p}}=0.1-0.5 \mathrm{wt} \%$, temperature $=27^{\circ} \mathrm{C}$, pulse delay time $=30 \mathrm{~s}$, and 16 scans.

particularly misleading to judge only from the ${ }^{1} \mathrm{H}$ NMR spectrum of PMeA in $\mathrm{D}_{2} \mathrm{O}$ whether the hydrolysis is complete or not. An apparent disappearance of $t$-butyl groups in ${ }^{1} \mathrm{H}$ NMR of PMeA in $\mathrm{D}_{2} \mathrm{O}$ is due to a hydrophobic association among $\alpha$-methyl groups and $t$-butyl groups at low pHs, as will be discussed later. In Figure 2(d), ${ }^{1} \mathrm{H}$ NMR spectrum of PMMA prepared from the PMeA sample further hydrolyzed using $\mathrm{HBr}$ is shown. In the spectrum, the degree of hydrolysis is calculated to be more than $99.9 \%$. Thus, we stress that two-step hydrolysis with $\mathrm{Si}\left(\mathrm{CH}_{3}\right)_{3} \mathrm{I}$ and with $\mathrm{HBr}$ is necessary to hydrolyze completely the high MW PTBA and PTBMA samples. In particular, the degree of hydrolysis for PMeA should be determined from ${ }^{1} \mathrm{H}$ NMR spectrum of the PMMA. It is worthy to note that we tried to hydrolyze PTBMA directly with $\mathrm{HBr}$ but failed.

To confirm the lack of chain breaking during the hydrolysis, SEC measurements were carried out for the poly(methyl acrylate) (PMA) and PMMA. The characterization results are listed in Tables I and II. One sees that the values of $M_{w} / M_{n}$ of PMA and PMMA are almost consistent with those of corresponding PTBA and PTBMA, implying that no chain breaking occurs during the hydrolysis. Therefore, we conclude that PAA 


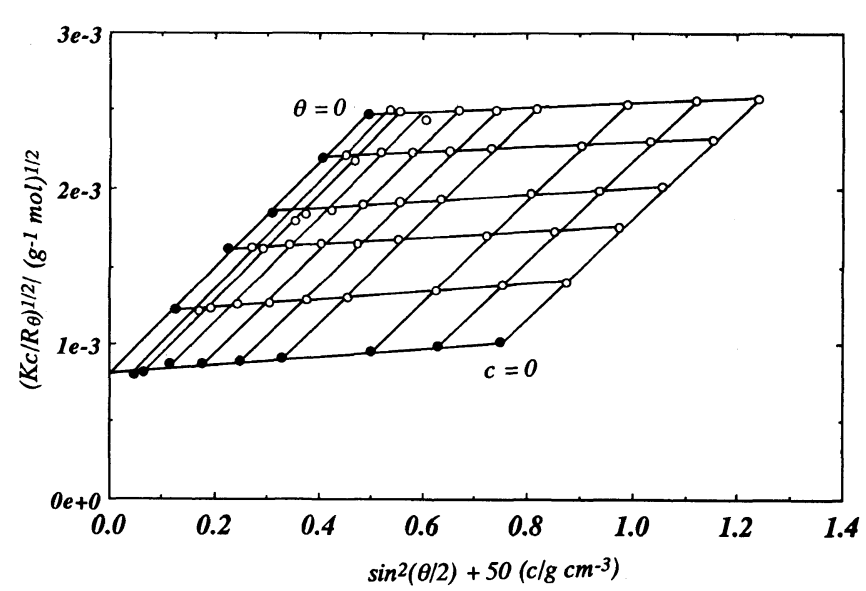

Figure 3. Zimm plot in the square-root form for PTBMA (run 1-D in Table II) in $n$-butyl acetate at $25^{\circ} \mathrm{C}$. The $M_{w}=1.5_{1} \times 10^{6}, A_{2}=$ $1.39 \times 10^{-5} \mathrm{~m}^{3} \mathrm{~mol} \mathrm{~kg}{ }^{-2}$, and $\left\langle S^{2}\right\rangle_{z}=2.7_{0} \times 10^{-11} \mathrm{~cm}^{2}$.

Table III. Molecular characteristics of PMA

\begin{tabular}{ccccc}
\hline Run & $10^{-4} M_{w \mathrm{LS}}{ }^{\mathrm{a}}$ & $10^{-4} M_{n \mathrm{VPO}} \mathrm{b}$ & $10^{-4} M_{w \mathrm{GPC}} \mathrm{c}^{\mathrm{c}}$ & $M_{w} / M_{n}{ }^{\mathrm{c}}$ \\
\hline 13 & & 0.31 & 0.33 & $1.2_{1}$ \\
14 & & 1.2 & 1.2 & $1.0_{6}$ \\
15 & & 1.91 & 2.1 & $1.1_{1}$ \\
16 & 3.9 & & 3.5 & $1.1_{9}$ \\
17 & 18.8 & & 13.6 & $1.1_{5}$
\end{tabular}

${ }^{\mathrm{a}}$ Determined by LS measurement. ${ }^{\mathrm{b}}$ Determined by VPO measurement. ${ }^{\mathrm{c}}$ Determined by SEC calibrated with a series of PMMA standard samples.

and PMeA samples, which are well-defined in MWD, are prepared by this method in $10 \mathrm{~g}$ scale over the molecular weight range of $10^{3}-10^{6}$.

\section{Characterization}

Figure 3 illustrates one example of the Zimm plot in the square-root form for the PTBMA sample (run 1-D) in $n$-butyl acetate at $25^{\circ} \mathrm{C}$. Here, $K$ is the optical constant given as $K=4 \pi^{2} n_{0}{ }^{2}(\mathrm{~d} n / \mathrm{d} c)^{2} /\left(\lambda_{0}{ }^{4} N_{\mathrm{A}}\right)$, and $R_{\theta}$, the reduced scattering intensity at scattering angle $\theta$ calculated on the basis of the Reyleigh ratio $R_{\mathrm{B}}=11.84 \times 10^{-6}$ $\mathrm{cm}^{-1}$ of pure benzene, ${ }^{25}$ where $n_{0}$ is the refractive index of the solvent, $(\mathrm{d} n / \mathrm{d} c)$, the specific refractive index increment, $\lambda_{0}$, the wavelength of the incident light, and $N_{\mathrm{A}}$, the Avogadro's number. For this sample, one obtains $M_{w}=1.51 \times 10^{6}, A_{2}=1.39 \times 10^{-5} \mathrm{~m}^{3} \mathrm{~mol} \mathrm{~kg}^{-2}$, and $\left\langle\mathrm{S}^{2}\right\rangle_{z}=2.7_{0} \times 10^{-11} \mathrm{~cm}^{2}$. The $M_{w}$ values from the light scattering measurements are presented in Tables I-IV, together with $M_{n}$ values determined from VPO measurements for the lower MW samples. One sees that the ratio of $M_{w}$ of PTBA (Table I) to $M_{w}$ of the corresponding PMA (Table III) is fairly consistent with that calculated from the monomer molecular weight of TBA and MA. This also suggests the absence of any chain breaking during the hydrolysis.

The stereoregularity of PMeA is an important parameter for the physical properties and was determined from the intensity ratio of $\alpha$-methyl protons signals in ${ }^{1} \mathrm{H}$ NMR spectra of PMMA (Figure 2(d)) and listed in Table IV. It is found that the triad tacticities are essentially independent of $\mathrm{MW}$ and almost constant, except for run 16. This seems an important information when one analyzes $\mathrm{pH}$-induced conformational transi-
Table IV. Molecular characteristics of PMMA

\begin{tabular}{|c|c|c|c|c|c|c|c|}
\hline \multirow{2}{*}{ Run } & \multirow{2}{*}{$10^{-4} M_{w \mathrm{LS}}{ }^{\mathrm{a}}$} & \multirow{2}{*}{$0^{-4} M_{n \mathrm{VPC}}$} & \multirow{2}{*}{$10^{-4} M_{w \mathrm{GPC}}{ }^{\mathrm{c}}$} & \multirow{2}{*}{$M_{w} / M_{n}^{\mathrm{c}}$} & \multicolumn{3}{|c|}{ Tacticities $/ \%^{\mathrm{d}}$} \\
\hline & & & & & $I$ & $H$ & $S$ \\
\hline 8 & & 0.16 & 0.17 & $1.0_{7}$ & 12.8 & 53.1 & 34.1 \\
\hline 9 & & 0.88 & 0.92 & $1.0_{9}$ & 14.8 & 51.5 & 33.7 \\
\hline 10 & & 0.96 & 1.1 & $1.0_{4}$ & 12.2 & 52.7 & 35.1 \\
\hline 11 & 2.84 & & 3.3 & $1.0_{4}$ & 14.1 & 51.6 & 34.3 \\
\hline 13 & 5.73 & & 5.9 & $1.0_{4}$ & 16.4 & 51.3 & 32.3 \\
\hline 15 & 12.2 & & 11 & $1.1_{0}$ & 15.2 & 51.1 & 33.7 \\
\hline 6 & 15.2 & & 15 & $1.1_{0}$ & 11.3 & 52.8 & 36.9 \\
\hline 16 & 31.6 & & 25 & $1.0_{6}$ & 7.7 & 45.0 & 47.0 \\
\hline 18 & 86.2 & & 84 & $1.2_{6}$ & 16.1 & 53.1 & 30.8 \\
\hline
\end{tabular}

${ }^{a}$ Determined by LS measurement. ${ }^{\mathrm{b}}$ Determined by VPO measurement. ${ }^{\mathrm{c}}$ Determined by SEC calibrated with a series of PMMA standard samples. ${ }^{\mathrm{d}}$ Determined by ${ }^{1} \mathrm{H}$ NMR intensity ratio of the peaks due to $\alpha$-methyl group (see Figure 2).

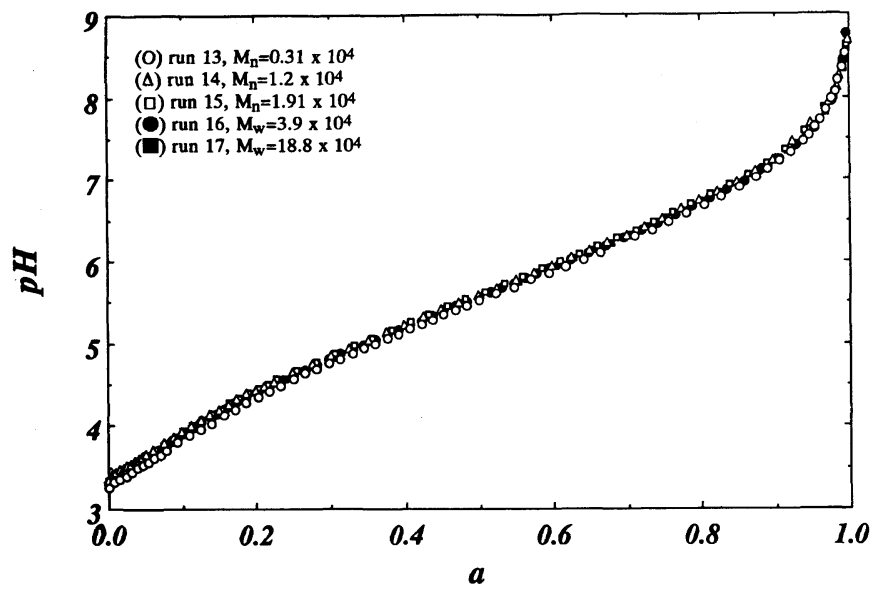

Figure 4. Potentiometric titration curves of PAA with different MWs in $C_{\mathrm{s}}=0.05 \mathrm{~N} \mathrm{NaCl}$ solution. The symbols correspond to the PAA samples in Table III: $(\bigcirc)$, run $13, C_{\mathrm{p}}=11.2 \mathrm{mN} ;(\triangle)$, run $14, C_{\mathrm{p}}=$ $10.2 \mathrm{mN} ;(\square)$, run $15, C_{\mathrm{p}}=10.0 \mathrm{mN} ;(\bullet)$, run $16, C_{\mathrm{p}}=11.2 \mathrm{mN} ;(\mathbf{\square})$, run $17, C_{\mathrm{p}}=10.1 \mathrm{mN}$.

tion of PMeA. The $\mathrm{pH}$ titration of polyelectrolytes depends on the tacticity. ${ }^{5}$

\section{Dissociation Properties}

Among the several physical properties of polyelectrolytes, we first investigated MW dependence on the potentiometric titration behavior which is one of the phenomena reflecting counterion condensation. Normal$1 \mathrm{y}$, it has been widely accepted that the potentiometric titration curve of the polyelectrolyte is essentially independent on MW, because the dissociation is determined by the short-range electrostatic interactions. PAA is a model case for this.

When the dissociation of polyelectrolyte produces a conformational transition from compact to expanded form, the free energy change corresponding to the transition is observed in the titration curve. One interesting question is whether the titration curve depends on MW or does not. PMeA is thought to be a model case.

The titration curves of PAA with various MWs at $C_{\mathrm{s}}=0.05 \mathrm{~N} \mathrm{NaCl}$ are shown in Figure 4, where the $\mathrm{pH}$ values are plotted against the degree of neutralization (a). One sees clearly that at least at $C_{\mathrm{s}}=0.05 \mathrm{~N}$ there is no MW dependence in MW range examined. The independence is observed over the whole range of $a$. 


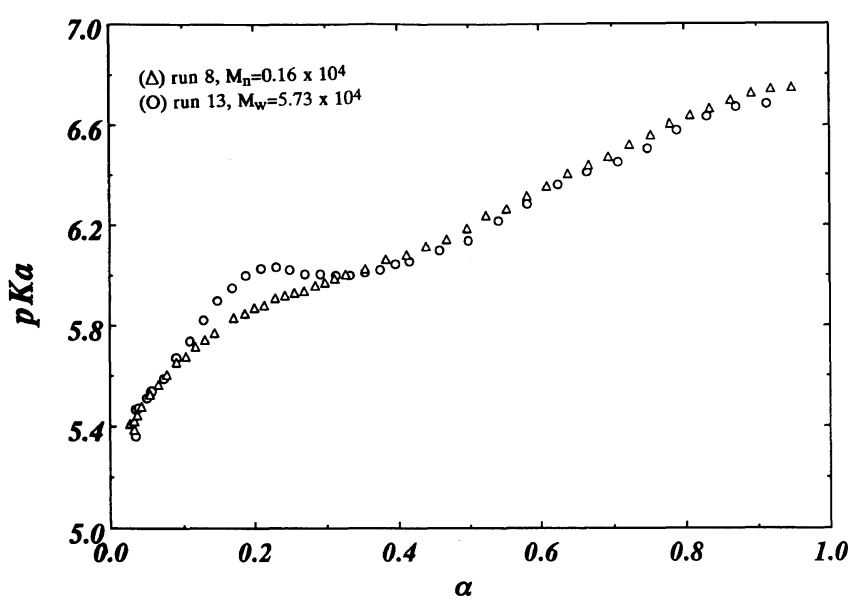

Figure 5. Potentiometric titration curves of PMeA in Table IV at $C_{\mathrm{s}}=0.05 \mathrm{~N} \mathrm{NaCl} .(\triangle)$, run $8, C_{\mathrm{p}}=5.76 \mathrm{mN} ;(\bigcirc)$, run $13, C_{\mathrm{p}}=4.22 \mathrm{mN}$.

Thus, it is concluded that the dissociation behavior of PAA is determined by the short-range electrostatic interaction but not by the long-range interaction term. Since in $C_{\mathrm{s}}=0.05 \mathrm{~N}, \kappa^{-1}$ is $13.6 \AA$ ( $\kappa$ is an inverse of Debye length) and corresponds to the chain length of ca. 5-6 mer, one must examine the titration behavior at much lower $C_{\mathrm{s}}$. At least $C_{\mathrm{s}}>0.05 \mathrm{~N}$, when the weightaverage degree of polymerization $\left(n_{w}\right)$ is greater than 36 (run 14, Table III), the characteristic electrical properties of the polyelectrolyte solution appear and become independent on the MW.

In Figure 5, the negative logarithm of apparent dissociation constant $\left(\mathrm{p} K_{\mathrm{a}}\right)$ of PMeA, defined by $\mathrm{pH}-$ $\log (\alpha /(1-\alpha))$ are plotted against the degree of dissociation $(\alpha)$. The $\mathrm{p} K_{\mathrm{a}}$ value of PMeA discontinuously increases with $\alpha$ in the low $\alpha$ region. This is a typical titration curve of hydrophobically modified polyelectrolytes in which the conformational transition from compact to extended form occurs. ${ }^{26,27}$ This is due to the balance between the hydrophobic and hydrophilic and/ or electrostatic interactions. Several experimental studies of this phenomenon in PMeA support this idea. ${ }^{28,29}$

One observes three interesting findings in the figure. First is that the discontinuous titration curve is observed even in the titration curve of PMeA with $n_{w}=17$. This implies that self-association among hydrophobic groups in PMeA chain may take place at $n_{w}<17$ to form a secondary structure. The transition occurs in the region of $0.05<\alpha<0.5$. Second one is that there exits clear MW dependence in the titration curve. The dependence is observed only in the transition region. In $\alpha>0.5$, where PMeA chains may assume a coil-like conformation, the $\mathrm{p} K_{\mathrm{a}}$ values are almost independent on the $\mathrm{MW}$, as observed in PAA. Third is that the transition occurs more evidently and sharply with higher MW PMeA than with a lower molecular weight one. We suspect that this transition is, more or less, due to a cooperative phenomenon. The results of detailed analysis will appear in the future publication, together with results of the conformational properties.

\section{CONCLUSIONS}

We report the preparation, characterization, and dis- sociation properties of PAA and PMeA with narrow MWDs over the MW range of $10^{3}-10^{6}$. They can be prepared by anionic polymerizations of TBA and TBMA in the presence of $\mathrm{LiCl}$, followed by two-step hydrolysis with $\mathrm{Si}\left(\mathrm{CH}_{3}\right)_{3} \mathrm{I}$ and $\mathrm{HBr}$. The careful characterizations including SEC, ${ }^{1} \mathrm{H}$ NMR, light scattering, and vapor pressure osmometry for the samples before and after the hydrolysis prove that well-defined PAA and PMeA with narrow MWDs are successfully prepared. In the potentiometric titration curve of PMeA a clear MW dependence is observed only in the transition region, while not in that of PAA.

Acknowledgment. The authors wish to thank the Ministry of Education, Science, and Culture of Japan for financial support of this work with Grants-in-Aid for the Encouragement of Young Scientists (No. 03750648) and (No. 04750735).

\section{REFERENCES}

1. A. Katchalsky, J. Polym. Sci., 6, 145 (1951); ibid., 23, 259 (1957).

2. J. C. Leyte and M. Mandel, J. Polym. Sci., A, 2, 1879 (1964).

3. M. Mandel, J. C. Leyte, and M. G. Stadhouder, J. Phys. Chem., 71, 603 (1967).

4. O. B. Ptitsyn, Vysokomolekul. Soedin., 7, 903 (1965).

5. M. Nagasawa, T. Murase, and K. Kondo, J. Phys. Chem., 69, 4005 (1965)

6. T. Kato, T. Tokuya, T. Nozaki, and A. Takahashi, Polymer, 25, 218 (1984).

7. M. Nagasawa, "Molecular Conformation and Dynamics of Macromolecules in Condensed Systems," Elsevier, New York, N.Y., 1988 and references cited in.

8. T. Kitano, T. Fujimoto, and M. Nagasawa, Polym. J., 9, 153 (1977).

9. T. Kitano, A. Taguchi, I. Noda, and M. Nagasawa, Macromolecules, 13, 537 (1980).

10. T. Odijk, J. Polym. Sci., Polym. Phys. Ed., 15, 477 (1977).

11. J. Skolnick and M. Fixman, Macromolecules, 10, 944 (1977).

12. R. Fayt, R. Forte, C. Jacobs, R. Jérôme, T. Ouhadi, and Ph. Teyssié, Macromolecules, 20, 1442 (1987).

13. S. K. Varshney, J.P. Hautekeer, R. Fayt, R. Forte, J. Jacobs, R Jérôme, and Ph. Teyssié, Macromolecules, 23, 2618 (1990).

14. T. Reetz, T. Knauf, U. Minet, and C. Bingel, Angew. Chem. Int. Ed. Engl., 27, 1373 (1988).

15. E. Ihara, M. Morimoto, and H. Yasuda, Macromolecules, 28, 7886 (1995)

16. R. D. Allen, T. E. Long, and J. E. McGrath, Polym. Bull., 15, 127 (1986).

17. L. Lochmann, M. Rodová, J. Petránek, and D. Lím, J. Polym. Sci., Polym. Chem. Ed., 12, 2295 (1974).

18. T. Morita, Y. Okamoto, and H. Sakurai, J. Chem. Soc., Chem. Commun., 874 (1978).

19. L. Lochmann and D. Lim, J. Organometallic Chem., 50, 9 (1973).

20. G. A. Olah and S. C. Narang, Tetrahedron, 38(15), 2225 (1982).

21. S. Kawaguchi, Y. Nishikawa, T. Kitano, K. Ito, and A. Minakata, Macromolecules, 23, 2710 (1990).

22. J. W. Klein, Y. Gnanou, and P. Rempp, Polym. Bull., 24, 39 (1990).

23. J. P. Hautekeer, S. K. Varshney, R. Fayt, G. Jabobe, R. Jérôme, and Ph. Teyssié, Macromolecules, 23, 3893 (1990).

24. T. Ishizone, A. Hirao, and S. Nakahama, Macomolecules, 22, 2895 (1989).

25. E. R. Pike, W. R. M. Pomeroy, and J. M. Vaughan, J. Chem. Phys., 62, 3188 (1975).

26. P. Dubin and U. P. Strauss, J. Phys. Chem., 71, 2757 (1967).

27. S. Sugai and T. Ohno, Macromolecules, 7, 961 (1974).

28. E. E. Kern and D. K. Anderson, J. Polym. Sci., A, 6, 2765 (1968).

29. H. Okamoto and Y. Wada, J. Polym. Sci., 12, 2413 (1974). 